\title{
Risk Factors for Breast Cancer in the City of Douala: A Case Control Study
}

\section{Engbang Ndamba Jean Paul ${ }^{1,2^{*}}$, Essome Henri ${ }^{1,2}$, Mve Koh Valère ${ }^{3}$, Sukam Noutadjeu Diane Sara ${ }^{1}$, Mboudou Telesphore Emile ${ }^{3,4}$}

\author{
${ }^{1}$ Faculty of Medicine and Pharmaceuticals Sciences of Douala, University of Douala, Douala, Cameroon \\ ${ }^{2}$ Laquintinie Hospital of Douala, Douala, Cameroon \\ ${ }^{3}$ Faculty of Medicine of Biomedical Sciences, University of Yaounde I, Yaounde, Cameroon \\ ${ }^{4}$ Gynaeco-Pediatric Hospital of Douala, Douala, Cameroon \\ Email: ^jpauleng@gmail.com, ^jean_pen@yahoo.ca, essometocky@yahoo.com,mvekoh@yahoo.com, \\ dianesynthiasukam@yahoo.fr, mboudoudoc@yahoo.fr
}

How to cite this paper: Paul, E.N.J., Henri, E., Valère, M.K., Sara, S.N.D. and Emile, M.T. (2020) Risk Factors for Breast Cancer in the City of Douala: A Case Control Study. Advances in Breast Cancer Research, 9, 66-77. https://doi.org/10.4236/abcr.2020.93006

Received: April 23, 2020

Accepted: May 24, 2020

Published: May 27, 2020

Copyright (อ 2020 by author(s) and Scientific Research Publishing Inc. This work is licensed under the Creative Commons Attribution International License (CC BY 4.0).

http://creativecommons.org/licenses/by/4.0/

\begin{abstract}
Background: The breast cancer is an abnormal proliferation of mammary gland cells. This condition as well as other cancers is globally increasing in the world. It is the most frequent malignancy of women in the world and is a public health problem. Generally in Africa and central Africa in particular, few studies have been realized in search of risk factors of breast cancer. It's all in this optical we began the study to determine the risk factors of this disease in the city of Douala. Patients and Methods: We conducted a case-control study, gave retrospectives collect on five years and prospectives collect on seven months. The studied population was all women aged 18 years and above with breast cancer diagnostic on histological plan for cases; and women from 18 years or more with normal physical examination and mammography. We have done our research in three reference hospitals of the city of Douala and two laboratories of pathological anatomy. The data were collected at the search files and the patients where interviewed. The parameters studied were: socio-demographic profile, clinic and Para clinic parameters, and the histological type. Results: At the end of this study, breast cancer is predominantly on young women in the city of Douala with a middle age of $44.08 \pm 2.6$ years. The most significant risk factors were age, age of the first birth $\geq 30$ years, age of the first sexual act $\leq 18$ years, low economic level, tobacco, hormonal contraceptive, parity. Conclusion: Finally, the malignancy of the breast takes a primordial place within the feminine population of Douala with many risk factors likes causes.
\end{abstract}

\section{Keywords}

Breast Cancer, Factors of Risk, City of Douala 


\section{Introduction}

Breast cancer is the most common and deadly malignant tumor in women worldwide with 410,000 deaths recorded in 2002 [1]. It ranks first in most countries and represents $23 \%$ of female cancers and $10.9 \%$ of all human cancers in the world [2]. In women, breast cancer was the most frequently diagnosed cancer in all regions of the world, except in Eastern Africa where cervical cancer dominated [3]. About 1 in 8 women in the US are at risk of developing invasive breast cancer. Between 1999 and 2005, there was a steady decline in cancer cases, observed only in women aged 50 and above [4]. Between 2010-2014 more than one in 10 breast cancer cases were late diagnosed in England, Scotland and Northern Ireland [2]. In France, the latest national estimates are those for 2012 with around 49,000 new cases of invasive breast cancer, corresponding to an annual gross rate of 148.5 cases per 100,000 women [5]. Cumulative African incidence and death due to breast cancer are 34.5 and 17.2 per 100,000 females [6]. In Africa, regional variability in incidence has been mentioned by Togo, including $16 \%$ in Senegal, $10 \%$ in the Republic of South Africa and 4\% in Kenya [7]. In North Africa, breast cancer is also the leading cancer for women and represents $14 \%$ to $42 \%$ of all female cancers; reason why the WHO considers this affection as a priority of public health in this region of the world [8]. Breast cancer is one of the leading causes of death from cancer in the least developed countries. This is partly because the changing lifestyles are causing an increase in the operation, but also because the clinical progress recorded against the disease does not benefit the women living in these regions [3]. Several factors can cause breast cancer, including advanced age, which is the main risk factor. The risk of developing breast cancer increases with age, and can reach women at very different ages [3]. Breast cancer is $7 \%$ higher per five year increment of oral contraceptive use and $14 \%$ higher per ten year increment [9]. Like other risk factors we have the reproduction; non-oral hormonal contraceptives, HRT; family history and genetic factors; genetic conditions (BRCA1 and 2); overweight and obesity; benign breast disease (atypical hyperplasia); ionizing radiation; alcohol; tobacco; professional exposures (ethylene oxide); medical conditions and treatments (dioxin, diethylstilbestrol, etc.); benign thyroid diseases and those of the breast [10].

In Cameroon, in 1992, breast cancer ranked second after cervical, skin and liver cancer [11]. In 2012 among the population of Yaoundé, breast cancer was the most common cancer in women with the brutal and age-standardized incidence rate of $25.89 \%$ and $35.25 \%$ respectively [12]. In 2015 , breast cancer was the cancer of young women in Cameroon with an average age of $46.58 \pm 15.72$ years [13]. These Cameroonian studies show that this pathology has experienced a sharp increase in recent years (having gone from 2nd to 1st place in 10 years) [11] [12]. In low-income countries like ours, this pathology is generally diagnosed at advanced stages; and the risk factors and prognosis for this condition have not yet been addressed. This is the reason why we propose to study the risk factors of breast cancer in the city of Douala in order to propose a preventive strategy. 


\section{Patients and Methods}

It was a case study with prospective and retrospective data collection. The study is carried out in three referral hospitals in the city of Douala. The study concerned all women aged 18 and over who had consulted in our study sites for the past five years, i.e. from January 1, 2012 to December 31, 2017 for the retrospective study and from November 25 to April 31, 2018 for the prospective study. The study was carried out on all women aged 18 and over who responded to the call for screening campaigns, or those simply recruited from hospitals during consultations and those followed for breast cancer. Concerning the cases, they were patients 18 years and older, carrying a breast cancer diagnosed histologically, having given their informed consent and whose clinical records were complete or completed by telephone. For controls, 18 years and over, with normal clinical and radiological examination, having given their informed consent and having replied to the questionnaire. For each case of cervical cancer, four controls were matched by age ( $<50$ years and $\geq 50$ years) and residence. Concerning controls, a sensitization of the women through the messages and communicators sent in different communities (Churches, meetings) of the city of Douala was carried out. Participants were enumerated and recorded daily for mass screening. After validation of the informed consent, a chart abstraction instrument was elaborated for collecting data from participant files. Information in files was collected by trained providers during systematic screening, and data were extracted retrospectively from those files stored in the two sites by providers from the respective sites. One dependent variable of interest was chosen, cervical cancer was defined as a binary variable. Independent variables included. Independent variables were: Socio-demographic parameters (age, profession of patient, residence, region and department of origin), Risk factors (age at first menstrual period, parity, age at first delivery, hormonal contraception, feeding with milk, history of high blood pressure, diabetes, mutilation of the breast; personal and/or family history of breast cancer; active and passive alcoholism and smoking, Sports practices, obesity, Height, Weight, use of insecticide).

Clinical and radiological parameters (inspection for asymmetry of the breast, with surface abnormality, breast ulceration, appearance of the breast in orange peel, granular, deviation or retraction of the nipple, deformation of the breast. Palpation for an irregular, often painless mass; presence of one or more lymph nodes. The expression in search of a bloody or transparent flow Depending on age the results of breast ultrasound or mammography).

The data previously collected on a file was transcribed digitally on computer by input, using XL stat software and Spss 22 23.0. We carried out in the foreground an analytical statistics in order to search the indicators with central tendency (average, mode) and the indicators with tendency of dispersion (standard deviation, variance); and frequency measurement was used to assess the level of the indicators. In the background we have a bi-varied, then multi-varied analysis in order to bring out the risk factors for breast cancer in the city of Douala. 
Simple text entry was made using Microsoft world 2007 software as long as the tables and graphs were made using Microsoft Excel 2007 software.

\section{Results}

\subsection{Distribution by Age}

In case group, the age of cases ranged from $25-82$ year with mean age of cases is $53.29 \pm 12.71$ years. In control group the mean age of the participants was 40.38 \pm 12.20 years from 17 to 77 years.

304 cases of breast cancer were recruited during our study. The average age was 48.05 years \pm 2.6 years with a minimum age of 18 and a maximum age of 80 . The modal class was [40 - 49] corresponding to a population of 90 cases $(29.6 \%)$ (Figure 1).

\subsection{Univariate Logistic Regression Analysis}

\subsubsection{Socio-Demographic Characteristics of Women Screened for Breast Cancer}

Table 1 shows that there is a significant association between socioeconomic level and breast cancer $(\mathrm{P}<0.05)$. Women with a low socio-economic level were twice as likely to develop breast cancer as those with a medium and high socio-economic level $(\mathrm{OR}=2.82$; $\mathrm{CI}=[2.17-3.66])$. The age distribution was significant between cases and controls with $27.3 \%$ of cases and $49.3 \%$ of controls had an age $<50$ years $(\mathrm{P}<0.05)$. Compared to women under the age of 50, women over the age of 50 were twice as likely to develop breast cancer ( $\mathrm{OR}=2.59$; $\mathrm{CI}=[1.96-3.41])$. The distribution by religion was significant with $10.5 \%$ of the cases and $24.8 \%$ of the controls who were Muslim $(\mathrm{P}<0.05)$. Compared to Muslim women, Christian women were twice as likely to develop breast cancer $(\mathrm{OR}=2.82 ; \mathrm{CI}=[1.9-4.18])$.

\subsubsection{Clinical Factors Associated with Breast Cancer}

\section{1) Medical and toxicological history}

As shown in Table 2, there is a significant association between the high-fat diet and breast cancer $(\mathrm{P}<0.05)$. Eating a diet high in fat increases the risk of developing breast cancer.

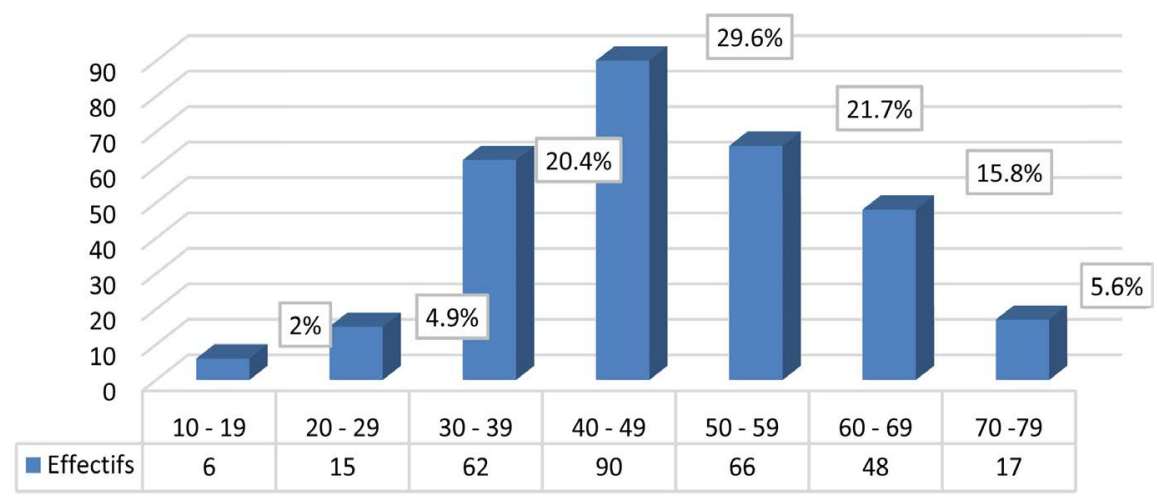

Figure 1. Distribution of cases by age. 
Table 1. Association between socio-demographic factors and breast cancer.

\begin{tabular}{cccccc}
\hline \multirow{2}{*}{ Variables } & Cases & Controls & P-Value & OR & 95\% CI \\
\cline { 2 - 3 } & $\mathbf{N}(\%)$ & $\mathbf{N}(\%)$ & & & \\
\hline Socio-economic status & $296(100)$ & $1204(100)$ & & & \\
Low & $176(59.5)$ & $412(34.2)$ & 0.001 & 2.82 & {$[2.17-3.66]$} \\
Midlle & $105(35.4)$ & $723(60.06)$ & & 0.37 & {$[0.28-0.48]$} \\
High & $15(5.1)$ & $69(5.74)$ & & 0.88 & {$[0.8-1.456]$} \\
Religion & $296(100)$ & $1204(100)$ & & & \\
Christian & $265(89.5)$ & $905(66.2)$ & & 2.82 & {$[1.9-4.18]$} \\
Muslim & $31(10.5)$ & $299(24.8)$ & $<0.0001$ & 0.35 & {$[0.24-0.52]$} \\
Age & $304(100)$ & $1210(100)$ & & & \\
$<50$ & $169(27.3)$ & $816(49.3)$ & $<0.0001$ & 0.39 & {$[0.3-0.51]$} \\
$\geq 50$ & $124(72.7)$ & $394(50.7)$ & & 2.59 & {$[1.96-3.41$} \\
\hline
\end{tabular}

Table 2. Association between medical history and breast cancer.

\begin{tabular}{|c|c|c|c|c|c|}
\hline \multirow{2}{*}{ Variables } & Cases & Controls & \multirow{2}{*}{ P-Value } & \multirow{2}{*}{ OR } & \multirow{2}{*}{$95 \%$ CI } \\
\hline & $\mathrm{N}(\%)$ & $\mathrm{N}(\%)$ & & & \\
\hline Permanent stress & $298(100)$ & $1210(100)$ & \multirow{3}{*}{0.001} & & \\
\hline No & $172(57.7)$ & $608(50.2)$ & & 1.35 & {$[1.32-3.22]$} \\
\hline Yes & $126(42.3)$ & $602(49.8)$ & & 0.74 & {$[0.57-0.96]$} \\
\hline AHT & $294(100)$ & $1010(100)$ & \multirow{3}{*}{0.13} & & \\
\hline Yes & $109(37.07)$ & $327(32.4)$ & & 1.23 & {$[0.94-1.61]$} \\
\hline No & $185(63.93)$ & $683(67.6)$ & & 0.81 & {$[0.62-1.06]$} \\
\hline Diabetes & $129(100)$ & $1210(100)$ & \multirow{3}{*}{0.23} & & \\
\hline No & $104(80.6)$ & $905(74.8)$ & & 1.31 & {$[0.83-2.07]$} \\
\hline Yes & $24(19.4)$ & $305(25.2)$ & & 0.76 & {$[0.48-1.2]$} \\
\hline STI & $230(100)$ & $1210(100)$ & \multirow{3}{*}{0.1} & & \\
\hline No & $120(52.17)$ & $632(52.2)$ & & 1.02 & {$[0.77-1.35]$} \\
\hline Yes & $110(47.3)$ & $578(47.8)$ & & 0.98 & {$[0.74-1.19]$} \\
\hline Fat-rich diet & $304(100)$ & $1210(100)$ & \multirow{3}{*}{0.001} & & \\
\hline Yes & $121(39.8)$ & $629(52)$ & & 0.61 & [0.47 - 0.79] \\
\hline No & $183(60.2)$ & $581(48)$ & & 1.64 & {$[1.27-2.12]$} \\
\hline Active tobacco & $304(100)$ & $1209(100)$ & \multirow{3}{*}{$<0.0001$} & & \\
\hline No & $282(92.8)$ & $1187(98.2)$ & & 0.24 & {$[0.13-0.44]$} \\
\hline Yes & $22(7.2)$ & $22(1.8)$ & & 4.21 & {$[2.3-7.71]$} \\
\hline Passive Tobacco & $250(100)$ & $1209(100)$ & \multirow{3}{*}{$<0.0001$} & & \\
\hline No & $104(41.6)$ & $793(65.6)$ & & 0.37 & {$[0.28-0.49]$} \\
\hline Yes & $146(58.4)$ & $416(34.4)$ & & 2.68 & {$[2.03-3.70]$} \\
\hline BMI Interprétation & $297(100)$ & $1200(100)$ & \multirow{4}{*}{$<0.0001$} & & \\
\hline$\leq 25$ & $68(22.9)$ & $452(37.42)$ & & 0.43 & {$[0.32-0.58]$} \\
\hline $25-30$ & $89(29.97)$ & $372(31)$ & & 0.96 & {$[0.73-1.27]$} \\
\hline$\geq 30$ & $140(47.13)$ & $379(31.58)$ & & 1.94 & {$[1.5-2.82]$} \\
\hline
\end{tabular}

**STI: Sexually transmitted infections, AHT: Arterial HyperTension. 
The distribution according to active smoking was significant between the cases and the controls, $7.2 \%$ of the cases and $1.8 \%$ of the controls did not smoke ( $\mathrm{P}$ $<0.05$ ). Compared with women who did not smoke, women who smoked were 4 times more likely to develop breast cancer $(\mathrm{OR}=4.21 ; \mathrm{CI}=[2.3-7.71])$. Passive smoking was significant between the cases and the controls, 58.4 of the cases and $34.4 \%$ of the controls were not exposed to tobacco smoke $(\mathrm{P}<0.05)$. Compared to women who were not, women who were exposed to tobacco smoke were twice as likely to develop breast cancer $(\mathrm{OR}=2.68 ; \mathrm{CI}=[2.03-3.70])$. The distribution according to BMI was significant between cases and controls, $(\mathrm{P}<0.05)$. Compared to women who were normal weight and those who were overweight, women who were obese were more likely to develop breast cancer $(\mathrm{OR}=1.94 ; \mathrm{CI}=[1.50-2.82])$.

\section{2) Reproductive and sexual factors}

There is a statistically significant association between the age of first sexual intercourse and breast cancer $(\mathrm{P}<0.05)$, as shown in Table 3. Women who had

Table 3. Univariate Logistic regression analysis for reproductive and sexual factors.

\begin{tabular}{|c|c|c|c|c|c|}
\hline & Cases & Controls & \multirow{2}{*}{ P-Value } & \multirow{2}{*}{ OR } & \multirow{2}{*}{$95 \% \mathrm{CI}$} \\
\hline Variables & N (\%) & N (\%) & & & \\
\hline Menarche & $244(100)$ & $898(100)$ & \multirow{3}{*}{0.601} & & \\
\hline $09-12$ years & $49(20.1)$ & $260(29)$ & & 0.62 & {$[0.44-0.88]$} \\
\hline 13 - 18 years & $195(79.9)$ & $638(71)$ & & 1.62 & {$[1.15-2.29]$} \\
\hline Age of first intercourse & $294(100)$ & $1202(100)$ & \multirow{3}{*}{$<0.0001$} & & \\
\hline$<18$ & $164(55.8)$ & $393(32.7)$ & & 2.597 & {$[2-3.36]$} \\
\hline$\geq 18$ & $130(44.2)$ & $809(67.3$ & & 0.39 & {$[0.3-0.51]$} \\
\hline Age of the first pregnancy & $270(100)$ & $939(100)$ & \multirow{3}{*}{0.013} & & \\
\hline$<30$ & $26(9.7)$ & $730(77.7)$ & & 0.03 & {$[0.02-0.05]$} \\
\hline$\geq 30$ & $244(90.3)$ & $209(22.3)$ & & 32.78 & {$[21.3-50.5]$} \\
\hline Parity & $295(100)$ & $1209(100)$ & \multirow{4}{*}{0.015} & & \\
\hline 0 & $42(14.23)$ & $167(13.8)$ & & 0.93 & {$[0.95-1.34]$} \\
\hline $1-3$ & $144(48.81)$ & $480(39.7)$ & & 1.54 & {$[1.3-1.98]$} \\
\hline$\geq 3$ & $119(36.96)$ & $562(46.5)$ & & 0.74 & {$[0.57-0.86]$} \\
\hline Average Breastfeeding Duration & $304(100)$ & $1210(100)$ & \multirow{4}{*}{$<0.0001$} & & \\
\hline 0 & $31(10.19)$ & $24(1.9)$ & & 5.61 & {$[3.24-9.71]$} \\
\hline $1-6$ mois & $179(58.8)$ & $631(52.14)$ & & 1.31 & {$[1.02-1.69]$} \\
\hline$\geq 6$ mois & $94(41.01)$ & $555(45.96)$ & & 0.53 & {$[0.57-0.96]$} \\
\hline Ménopause & $298(100)$ & $1209(100)$ & \multirow{3}{*}{$<0.0001$} & & \\
\hline Non & $151(50.7)$ & $770(63.7)$ & & 0.59 & {$[0.46-0.76]$} \\
\hline Oui & $147(49.3)$ & $439(36.3)$ & & 1.71 & {$[1.32-2.21]$} \\
\hline Contraception & 297 (100) & $1158(100)$ & \multirow{3}{*}{$<0.0001$} & & \\
\hline Non & $147(83.2)$ & $733(63.3)$ & & 0.59 & {$[0.46-0.76]$} \\
\hline Oui & $150(16.8)$ & 425 (36.7) & & 1.69 & [1.31-2.19] \\
\hline
\end{tabular}


their first sexual intercourse before 18 years of age were twice as likely to develop breast cancer than those who had it after 18 years $(\mathrm{OR}=2.597 ; \mathrm{CI}=[2.003$ 3.367]). There is also a statistically significant association between age at first delivery and breast cancer $(\mathrm{P} \leq 0.05)$. Women who had their first child over 30 were thirty-two times more likely to develop breast cancer than those who had their first child before $30(\mathrm{OR}=32.78$; $\mathrm{CI}=[21.27-50.52])$. The distribution according to parity was relatively significant between the cases and the controls $(\mathrm{P}<0.05)$. Compared to nulliparous women compared to women who had more than 3 full-term pregnancies, those who had between 1 - 3 full-term pregnancies were more likely to develop breast cancer $(\mathrm{OR}=1.54$; $\mathrm{CI}=[1,3-1.98])$. The duration of breastfeeding was significant between cases and controls $(\mathrm{P}<0.05)$. Compared to breastfeeding women, those who were breastfeeding were 5 times more likely to develop breast cancer $(O R=5.61 ; C I=[3.24-9.71])$. Similarly, a statistically relatively significant association was found between menopause and breast cancer $(\mathrm{P}<0.05)$. Postmenopausal women were more likely to develop breast cancer than those who were not $(\mathrm{OR}=1.71 ; \mathrm{CI}=[1.32-2.21])$. The distribution according to hormonal contraception was also relatively significant between the cases and the controls $(\mathrm{P}<0.05)$. Compared to women who had never been on hormonal contraception, women who were on contraception were more likely to develop breast cancer $(\mathrm{OR}=1.69 ; \mathrm{CI}=[1.31-2.19])($ Table 3$)$.

\subsection{Multivariate Regression}

According to Table 4, patients with a low socio-economic level were twice as likely to develop breast cancer as those belonging to a medium and high socio-economic level. $(\mathrm{ORa}=2.08$ with $\mathrm{CIa}=[1.48-2.92])$, adjusting for the other variables in the model. Patients who smoked were 6 times more likely to develop breast cancer than those who did not smoke $(\mathrm{ORa}=6.71$ with $\mathrm{CIa}=[3.13-$ 14.28]), adjusting to the other variables in the model. Patients who had their first deliveries after 30 years were twice as likely to develop breast cancer as those who had them before 30 years $(\mathrm{OR}=2.59$ with $\mathrm{CIa}=[1.38-4.87])$, by adjusting to the other variables of the model. Patients who had their 1st intercourse before 18 years were more likely to develop breast cancer than those who had it after

Table 4. Risk factors of Breast cancer.

\begin{tabular}{cccc}
\hline Risk factors & OR ajust & 95\% CI & P Value \\
\hline Low socio-economic status & 2.08 & {$[1.48-2.92]$} & $<0.0001$ \\
Age $\geq \mathbf{5 0}$ & 1.17 & {$[0.71-1.94]$} & 0.04 \\
Active tobacco & 6.71 & {$[3.13-14.28]$} & $<0.0001$ \\
Age first intercourse $<$ 18 & 1.84 & {$[1.33-2.56]$} & 0.000 \\
Age of the first pregnancy $\geq 30$ & 2.59 & {$[1.38-4.87]$} & 0.003 \\
Parity 0 & 2.82 & {$[1.50-5.31]$} & 0.001 \\
Hormonal contraception & 1.56 & {$[0.68-3.19]$} & $<0.0001$ \\
\hline
\end{tabular}


18 years $(\mathrm{ORa}=1.81$ with $\mathrm{CIa}=[1.33-2.56])$, by adjusting to the other variables of the model. Patients who had been on hormonal contraception were relatively more likely to develop breast cancer than those who had never been on contraception $(\mathrm{ORa}=1.56$ with $\mathrm{CIa}=[0.71-1.94])$, adjusting to the other variables of the model. Patients who had never had a full-term pregnancy were 2.82 more likely to have breast cancer than those who had ever had it (ORa $=2.82$ with CIa $=[1.50-1.50])$.

\section{Discussion}

A total of 1520 women were recruited; 304 cases and 1216 controls. The mean age was $48.05 \pm 2.6$ years for the cases and $42.87 \pm 2.2$ years for the controls. Those mean ages were similar to the study done in Iran, (Cases: $41.24 \pm 5.71$ years and controls: $41.06 \pm 5.81$ years) [14].

Our study demonstrated that there is a significant association between age $\geq$ 50 and breast cancer $(\mathrm{OR}=2.59 ; \mathrm{CI}=[1.96-3.41])$, Compared to women younger than 50 years of age, women 50 years and older were twice as likely to develop breast cancer. Adjusted for other variables, age $\geq 50$ years $(\mathrm{ORa}=1.17$ with CIa $=[0.71-1.94])$. Indeed, cell growth and development leads to possibilities of damage or genetic mutation. It is from these errors that cancer cells are born in our organism and more precisely in our case in mammary gland cells. These cancer cells have the ability to grow and multiply over time. According to Kamińska et al., the aging process is the greatest risk factor for breast cancer [15]. A very interesting correlation can be observed between the age when neoplastic disease is diagnosed and the expression of the estrogen receptor found in the examined tumor tissue. Neoplasms showing estrogen receptor overexpression ER $(+)$ are characterized by a frequency increasing with age as opposed to ER (-) tumors, which occur more frequently up to 50 years of age and then reach a plateau. This phenomenon explains an increased percentage of ER (+) tumors diagnosed in women after menopause [16]. But in our study, this association was not such significant in multivariate analysis. It seems that association of age $\geq 50$ with risk of breast cancer is mostly due to other factors.

The prevalence of breast cancer was higher in patients with a low socio-economic level $(59.5 \%)$. The majority of cases included in this social class were housewives with a workforce of $145(82.39 \%)$ cases. The distribution by socioeconomic status has shown that there is a significant association between low socioeconomic level and breast cancer. Patients with a low socio-economic level were twice as likely to have breast cancer as those belonging to a medium and high socio-economic level. After adjustment to other variables in multivariate analysis, this association remains significant $(\mathrm{ORa}=2.08$ with $\mathrm{CIa}=[1.48-2.92])$. These results are contradictory with those carried out in Western countries. The study by Robert S et al. found that, women living in the highest socioeconomic communities had greater odds of having breast cancer than women living in the lowest SES communities (1.20; 95\% confidence interval $=1.05-1.37)$ [17].

Parity was significant between cases and controls $(\mathrm{P}<0.05)$. Compared to 
women who had more than 6 full-term pregnancies, those who had never had a higher risk of developing breast cancer $(\mathrm{ORa}=2.82$ with $\mathrm{CIa}=[1.50-1.50]) . \mathrm{A}$ study done on Iranian women in 2011 found a significant association between breast cancer and parity with an $\mathrm{OR}=2.74$ for nulliparous women, $\mathrm{OR}=0.33$ for women who had between 1 and 2 pregnancies and one $\mathrm{OR}=0.16$ for women who have had more than three children [14]. According to some authors, Breast cancer risk decreases by 7\% with each live birth [18] [19]. That's suggesting that having children appears to have the strongest protective effect on breast cancer risk.

In 2011, Mervels P et al., who showed that the risk of breast cancer is high when the first delivery is late and it seems to decrease if the first delivery is before 30 years [20].

In our study, the bi-varied analysis showed a significant association between age at first delivery and breast cancer $(\mathrm{P} \leq 0.05)$. Women who had their first child over 30 were 32 times more likely to develop breast cancer than those who had their first child before $30(\mathrm{OR}=32.78$; $\mathrm{CI}=[21.27-50.52])$. Adjust to other variables, the age above 30 years at the first delivery remains significant $(\mathrm{OR}=$ 2.59 with $\mathrm{CI}=[1.38$ - 4.87] $)$. According to some studies, Breast cancer risk increases by $3 \%$ for each year older a woman is when she first gives birth [18]. Younger age at first full-term pregnancy has been known as a protective factor in the lifetime risk of developing breast cancer. A plausible explanation for the protection effect is due to the higher degree of terminal differentiation of mammary epithelial cells at first birth, which makes the epithelium able to metabolize carcinogens and repair DNA damage more efficiently [21].

The prevalence of smoking among patients was $55.26 \%$ (168), of which $7.2 \%$ for active smoking and $58.4 \%$ for passive smoking. We found a significant association between smoking and breast cancer, $(\mathrm{P}<0.05)$. Compared to women who did not smoke, women who smoked were more likely to develop breast cancer $(\mathrm{OR}=4.21 ; \mathrm{CI}=[2.30-7.71])$ for active smoking and $(\mathrm{OR}=2.68 ; \mathrm{CI}=$ [2.03 - 3.54]) for passive smoking. But when adjusted by other variables, only active smoking remained significant. Hanaoka et al. found that both active and passive smoking were associated with an increased risk of breast cancer among premenopausal women [22]. Henoui et al., Affirmed that women who smoked passively were 3.58 more likely to developed breast cancer [23]. Some authors shown that Breast cancer risk is $7 \%-13 \%$ higher in current smokers, and $6 \%$ 9\% higher in former smokers, compared with never-smokers [24] [25] [26]. A meta-analysis found a significant interaction between smoking, $\mathrm{N}$-acetyltransferase 2 (NAT2) genotype, and risk of breast cancer: higher pack-years were associated with an increased risk among women with the NAT2 slow genotype, but not among rapid acetylators [27].

According to our study, a significant association exists between the age at first sexual intercourse (sexarche) and breast cancer $(\mathrm{P}<0.05)$. Women who had their first sexual intercourse before 18 years of age were twice as likely to have breast cancer than those who had it after 18 years $(\mathrm{OR}=2.597 ; \mathrm{CI}=[2.003-$ $3.367]$ ). Adjusted for other variables, it remained relatively significant (ORa $=$ 
1.81 with CIa $=[1.33-2.56])$. Although, Babita et al. found that women who got married (sexarche) before 15 years of age have decreased risk to have breast cancer $(\mathrm{OR}=0.46, \mathrm{CI}=0.27-0.79)[28]$.

\section{Conclusion}

Breast cancer can be considered as cancer of the young woman in the city of Douala (Cameroon), with an average age of 48.05 years \pm 2.6 years. This study allowed us to find the risk factors for breast cancer in the city of Douala during the past five years, the most emphasized of which was the age at first delivery greater than 30 years with a frequency of $90.3 \%$, low socio-economic level; age $\geq$ 50 , hormonal contraception.

\section{Contributions of the Authors}

Author Engbang designed the study, wrote the protocol and wrote the first draft of the manuscript. Authors Essome and Sukam participated in data collection supervision and analysis. Author Mve Koh contributed in literature search. Author Mboudou reviewed the final manuscript. All authors read and approved the final.

\section{Conflicts of Interest}

The authors declare no conflicts of interest regarding the publication of this paper.

\section{References}

[1] Anderson, B.O., et al. (2008) Guideline Implementation for Breast Healthcare in Low-Income and Middle-Income Countries: Overview of the Breast Health Global Initiative Global Summit 2007. Cancer, 113, 2221-2243.

https://doi.org/10.1002/cncr.23844

[2] Ferlay, J., Soerjomataram, I., Ervik, M., Dikshit, R., Eser, S., Mathers, C., et al. (2013) Globocan 2012 v1.0, Cancer Incidence and Mortality Worldwide: IARC Cancer Base No. 11 International Agency for Research on Cancer, Lyon, France.

[3] Ferlay, J., Colombet, M., Soerjomataram, I., Mathers, C., Parkin, D.M., Piñeros, M., et al. (2019) Estimating the Global Cancer Incidence and Mortality in 2018: GLOBOCAN Sources and Methods. International Journal of Cancer, 144, 1941-1953. https://doi.org/10.1002/ijc.31937

[4] Ferlay, J., Shin, H.R., Bray, F., Forman, D., Mathers, C. and Parkin, D.M. (2010) Estimates of Worldwide Burden of Cancer in 2008: GLOBOCAN 2008. International Journal of Cancer, 127, 2893-2917. https://doi.org/10.1002/ijc.25516

[5] Binder-Foucard, F., Bossard, N., Delafosse, P., Belot, A., Woronoff, A.S., Remontet, L., et al. (2014) Cancer Incidence and Mortality in France over the 1980-2012 Period: Solid Tumors. Revue d Épidémiologie et de Santé Publique, 62, 95-108. https://doi.org/10.1016/j.respe.2013.11.073

[6] Zeru, Y., Sena, L. and Shaweno, T. (2019) Knowledge, Attitude, Practice, and Associated Factors of Breast Cancer Self-Examination among Urban Health Extension Workers in Addis Ababa, Central Ethiopia. Journal of Midwifery and Reproductive Health, 7, 1662-1672. https://doi.org/10.22038/jmrh.2019.32555.1355

[7] Togo, A., Traore, A., Traore, C., Dembele, B.T., Kante, L., Diakite, I., et al. (2010) 
Cancer du sein dans deux centres hospitaliers de Bamako (Mali): Aspects diagnostiques et thérapeutiques. Journal africain du cancer, 2, 88-91.

https://doi.org/10.1007/s12558-010-0060-x

[8] El Saghir, N.S., Khalil, M.K., Eid, T., El Kinge, A.R., Charafeddine, M., et al. (2017) Trends in Epidemiology and Management of Breast Cancer in Developing Arab Countries: Literature and Registry Analysis. International Journal of Surgery, 5, 225-233. https://doi.org/10.1016/j.ijsu.2006.06.015

[9] Zhu, H., Lei, X., Feng, J. and Wang, Y. (2012) Oral Contraceptive Use and Risk of Breast Cancer: A Meta-Analysis of Prospective Cohort Studies. European Journal of Contraception and Reproductive Health Care, 17, 402-414. https://doi.org/10.3109/13625187.2012.715357

[10] Loubser, F., Edge, J. and Fieggen, K. (2008) Epidemiology, Risk Factors and Genetics of Breast Cancer. Continuing Medical Education, 26, 497-501.

[11] Mbakop, A., Yomi, J., Yankeum, J., Nkegoum, B. and Sone, A.M. (1997) Localisations des cancers chez les hommes et les femmes âgés de plus de 50 ans au Cameroun. Bulletin du Cancer (Paris), 84, 1119-1122.

[12] Enow Orock, G.E., Ndom, P., Doh, A.S., et al. (2012) Current Cancer Incidence and Trends in Yaounde, Cameroon. Oncology, Gastroenterology and Hepatology Reports, 1, 58-63. https://doi.org/10.5530/ogh.2012.1.14

[13] Engbang, J.P.N., Essome H., Koh, V.M., Simo, G., Essam, J.D.S., Mouelle, A.S. and Essame, J.L.O. (2015) Cancer du sein au Cameroun, profil histo-épidémiologique: À propos de 3044 cas. Pan African Medical Journal, 21, 242. https://doi.org/10.11604/pamj.2015.21.242.7269

[14] Ghiasvand, R., Maram, E.S., Tahmasebi, S. and Tabatabaee, S.H.R. (2011) Risk Factors for Breast Cancer among Young Women in Southern Iran. International Journal of Cancer, 129, 1443-1449. https://doi.org/10.1002/ijc.25748

[15] Kamińska, M., Ciszewski, T., Łopacka-Szatan, K., Miotła, P. and Starosławska, E. (2015) Breast Cancer Risk Factors. Przeglad Menopauzalny, 14, 196-202. https://doi.org/10.5114/pm.2015.54346

[16] Ban, K.A. and Godellas, C.V. (2014) Epidemiology of Breast Cancer. Surgical Oncology Clinics of North America, 23, 409-422. https://doi.org/10.1016/j.soc.2014.03.011

[17] Robert, S.A., Strombom, I., Trentham-Dietz, A., Hampton, J.M., McElroy, J.A., et al. (2004) Socioeconomic Risk Factors for Breast Cancer: Distinguishing Individualand Community-Level Effects. Epidemiology, 15, 442-450. https://doi.org/10.1097/01.ede.0000129512.61698.03

[18] Collaborative Group on Hormonal Factors in Breast Cancer (2002) Breast Cancer and Breastfeeding: Collaborative Reanalysis of Individual Data from 47 Epidemiological Studies in 30 Countries, Including 50302 Women with Breast Cancer and 96973 Women without the Disease. The Lancet, 360, 187-195.

https://doi.org/10.1016/S0140-6736(02)09454-0

[19] Ma, H., Bernstein, L., Pike, M.C., et al. (2006) Reproductive Factors and Breast Cancer Risk According to Joint Estrogen and Progesterone Receptor Status: A Meta-Analysis of Epidemiological Studies. Breast Cancer Research, 8, R4. https://doi.org/10.1186/bcr1525

[20] Merviel, P., Jouvance, O., Naepels, P., Fauvet, R., Gagneur, O., Gondry, J., et al. (2011) Existe-t-il encore des facteurs de risque desurvenu de cancer du sein? Gynecologie Obstetrique et fertilite, 39, 486-490. https://doi.org/10.1016/j.gyobfe.2010.10.015 
[21] Russo, J., Moral, R., Balogh, G., Mailo, D. and Russo, I. (2005) The Protective Role of Pregnancy in Breast Cancer. Breast Cancer Research, 7, 131-142. https://doi.org/10.1186/bcr1029

[22] Hanaoka, T., Yamamoto, S., Sobue, T., Sasaki, S. and Tsugane, S. (2005) Active and Passive Smoking and Breast Cancer Risk in Middle-Aged Japanese Women. International Journal of Cancer, 114, 317-322. https://doi.org/10.1002/ijc.20709

[23] Henaoui, L., Meguenni, K. and Oudjhih, M. (2018) Épidémiologie et Facteurs de Risque du Cancer du Sein: Étude Cas-Témoins. Universitaires Europeennes, Beau Bassin.

[24] Gaudet, M.M., Gapstur, S.M., Sun, J., et al. (2013) Active Smoking and Breast Cancer Risk: Original Cohort Data and Meta-Analysis. Journal of the National Cancer Institute, 105, 515-525. https://doi.org/10.1093/jnci/djt023

[25] Gaudet, M.M., Carter, B.D., Brinton, L.A., et al. (2017) Pooled Analysis of Active Cigarette Smoking and Invasive Breast Cancer Risk in 14 Cohort Studies. International Journal of Epidemiology, 46, 881-893. https://doi.org/10.1093/ije/dyw288

[26] Macacu, A., Autier, P., Boniol, M., et al. (2015) Active and Passive Smoking and Risk of Breast Cancer: A Meta-Analysis. Breast Cancer Research and Treatment, 154, 213-224. https://doi.org/10.1007/s10549-015-3628-4

[27] Ambrosone, C.B., Kropp, S., Yang, J., Yao, S., Shields, P.G. and Chang-Claude, J. (2008) Cigarette Smoking, N-Acetyltransferase 2 Genotypes, and Breast Cancer Risk: Pooled Analysis and Meta-Analysis. Cancer Epidemiology, Biomarkers \& Prevention, 17, 15-26. https://doi.org/10.1158/1055-9965.EPI-07-0598

[28] Babita, R., Kumar, N., Karwasra, R.K., Singh, M., Malik, J.S. and Kaur, A. (2014) Reproductive Risk Factors Associated with Breast Carcinoma in a Tertiary Care Hospital of North India: A Case-Control Study. Breast Cancer Symposium, 51, 251-255. https://doi.org/10.4103/0019-509X.146759 